\title{
Brown ring disease in the Manila clam Ruditapes philippinarum: establishment of a classification system
}

\author{
C. Paillard, P. Maes \\ URA CNRS 1513, Institut Universitaíre Européen de la Mer, Université de Bretagne Occidentale, F-29287 Brest Cedex, France
}

\begin{abstract}
The main sign characterizing brown ring disease (BRD) in Manila clam Ruditapes philippinarum is a brown conchiolin deposit on the inner surface of the shell. Different stages of deposit formation and of the shell repair process were examined by means of binocular microscopy. The surface area of the deposit was quantified by image analysis and its precise location was determined. Experimental induction of brown ring syndrome after infection with a Vibrio sp. (VP1) allowed us to follow the evolution of macroscopic modifications in the shell inner surface. Simultaneously with the development of $\mathrm{BRD}$, a shell repair process generally occurs. Based on these macroscopic observations, a classification of BRD is proposed.
\end{abstract}

KEY WORDS: Shell disease - Vibrio - Bivalvia Conchiolin

\section{INTRODUCTION}

Since 1977, the culture of a non-native venerid clam, Ruditapes philippinarum, has developed extensively along the French Atlantic coast. In 1987, in the northwest of Brittany (Brouennou locality), mass mortalities of the clams were associated with a shell anomaly called brown ring disease (BRD). The main sign characterizing the disease is a brown conchiolin deposit on the inner surface of the valves, generally located between the pallial line and the edge of the shell (Paillard et al. 1989, Paillard 1992). A Vibrio sp., subsequently called Vibrio P1 or VP1, was isolated and defined as the etiological agent responsible for this disease (Paillard \& Maes 1990, Maes 1992). Similar syndromes have already been described in other bivalves but were associated with other causes: oxygen oversaturation (Malouf et al. 1972), nutritional deficiencies (Mori 1975), or parasites (Dollfus 1912, Alderman \& Jones 1967, 1971, Farley 1968, Quayle 1969, Bartoli 1974). In shell disease caused by a fungus identified as Ostracoblabe implexa, the authors (Alderman \& Jones 1971) defined stages of conchiolin deposition in wild oysters Ostrea edulis and Crassostrea angulata, but experimental induction of the disease was slow and produced low levels of infected individuals and it was therefore not possible to follow the development of the disease. In the present study, an attempt was made to describe the BRD syndrome qualitatively and quantitatively. The surface area occupied by it was measured by image analysis and its exact location determined. Infection of healthy clams by VP1 allowed us to follow the development of the syndrome. The experimentally induced syndrome was then compared with the conchiolin deposit in naturally diseased clams. The aim of this study was to classify the syndrome in stages corresponding to the development of BRD.

\section{MATERIALS AND METHODS}

Clams. Healthy and diseased juvenile (10 to $20 \mathrm{~mm}$ length) and adult (20 to $40 \mathrm{~mm}$ length) Manila clams Ruditapes philippinarum were collected from clam beds in Brouennou (Landéda, North Finistère, France) from January to June 1988. Two types of clams were defined according to their location in the sediment: burrowing clams, which are normally buried in the 
sediment, and surfacing clams, which rise to the sediment surface prior to death. Juvenile Manila clams were also obtained directly from hatcheries. These were maintained in marine aquaria and fed twice weekly with Dunaliella sp. Periodic examination of the clam tissues indicated that they remained in a healthy condition for an extended period of time.

Infection experiments. For all the VP1 injections, a bacterial suspension of $10^{8}$ cells $\mathrm{ml}^{-1}$ sterile seawater was used. Suspensions were obtained from bacterial cultures 72 h old (Paillard \& Maes 1990). Prior to infection, healthy clams were left out of water for $5 \mathrm{~h}$. Following re-immersion, the clams opened their valves, at which time a syringe needle was introduced between the edges of the valves without damaging the shell. The clams were again removed from the water and a suspension (0.1 $\mathrm{ml}$ per individual of 10 to $15 \mathrm{~mm}$ length) was injected into the pallial cavity. For all the experiments, 2 batches of 150 individuals were injected and 2 batches of 150 individuals were used as controls.

Quantitative analysis of the deposit. Images of the inner surface of each valve were obtained using a video camera (camera: CCD; card: MATROX MVP/ AT), taking care that the optical axis of the camera was perpendicular to the plane defined by the edge of the valves. The images were then processed with an image analyzer (Visilog 3.6 on a Silicon Graphic Personal Iris $4 \mathrm{D} 25$ workstation) to estimate the surface area of the deposit $\left(S_{\mathrm{D}}\right)$ and the entire inner surface area of the valve $\left(S_{V}\right)$. The measured surfaces did not correspond to the real surface area of the valve, but rather to the orthogonal projection on the defined plane of the edge of the shell. In this way, a deposit surface index (DSI) was calculated: $\mathrm{DSI}=\left(S_{\mathrm{D}} / S_{\mathrm{V}}\right) \times 100$. This index can be calculated for the right, the left or both valves.

\section{RESULTS}

\section{Description of the syndrome}

\section{Macroscopical appearance}

The typical sign of BRD is visible to the naked eye on the inner surface of the shell: an abnormal organic brown material, generally adhering to the area between the pallial line and the edge of the shell (Fig. 1). It is made up of several superimposed layers, which give it a laminated structure. When the deposit is very thick, it takes on a darker coloration and its surface may display a series of radially oriented crests (Figs. 2 \& 4). During the early part of disease development, when the deposit cannot be seen without a magnifying glass $(25 \times), 2$ signs present together or separately permit identification of the BRD syndrome. The first sign is an organic film made up of 1 or several layers, pale brown in color, strongly adhering to the inner edge of the shell (see Fig. 11a, b), and the second is several small brown spots surrounded by a pale brown halo, arranged in radial lines at the inner edge of the shell (see Fig. 11a, b).

Regardless of its thickness, the deposit can be invaded by shell secretions, which may be either small calcified concretions (Figs. $3 \& 4$ ) or wide plates, porcellaneous in appearance, covering the conchiolin deposit (Figs. 5 to 7 ). When the shell repair process is more advanced, it may result in a complete regeneration of the inner shell layers (Figs. 6 \& 7). Such shell repair was observed in naturally diseased clams collected from January to June 1988. In January, the deposit was mainly made up of organic material (Fig. 2). From February to March, carbonate crystals studded the surface of the deposit, giving it a floccllent appearance (Figs. 3 \& 4). During April and May, wide calcified plates, similar in appearance to the inner layer of the shell, partially covered the deposit (Fig. 5). In June, 70\% of the clams exhibited a brown ring partially or completely covered by a calcified porcellaneous layer (Figs. 6 \& 7). In cases where the calcified layer was recent and therefore transparent, the deposit was still visible (Fig. 5). However, when the calcified layer was thick, the deposit was detectable by the unevenness of the surface of the calcified layer corresponding to the crests of the deposit (Fig. 7)

\section{Deposit surface index}

Among the 288 clams collected from January to June 1988, 563 valves displayed a brown deposit and 13 valves were undamaged. The distribution of the DSI was significantly different between the surfacing and the burrowing clams for all months (KolmogorovSmirnov test of frequency comparison, $p=0.05$ ) (Fig. 8 ). For all the examined valves, the DSI varied from 0 to 30. Depending on the month, between 40 and $74 \%$ of burrowing clams exhibited a relatively low index (from 0 to 5); this DSI category was more frequent in April and June than in other months. For all months, a DSI greater than 15 was seen in only 8 to $20 \%$ of burrowing clams and in 40 to $80 \%$ of surfacing clams. Therefore, surfacing clams were more frequently affected by deposits covering a greater surface area than burrowing clams.

\section{Brown deposit localization}

The inner surface of each clam valve can be divided into 4 compartments: the peripheral, the sinusal, the 

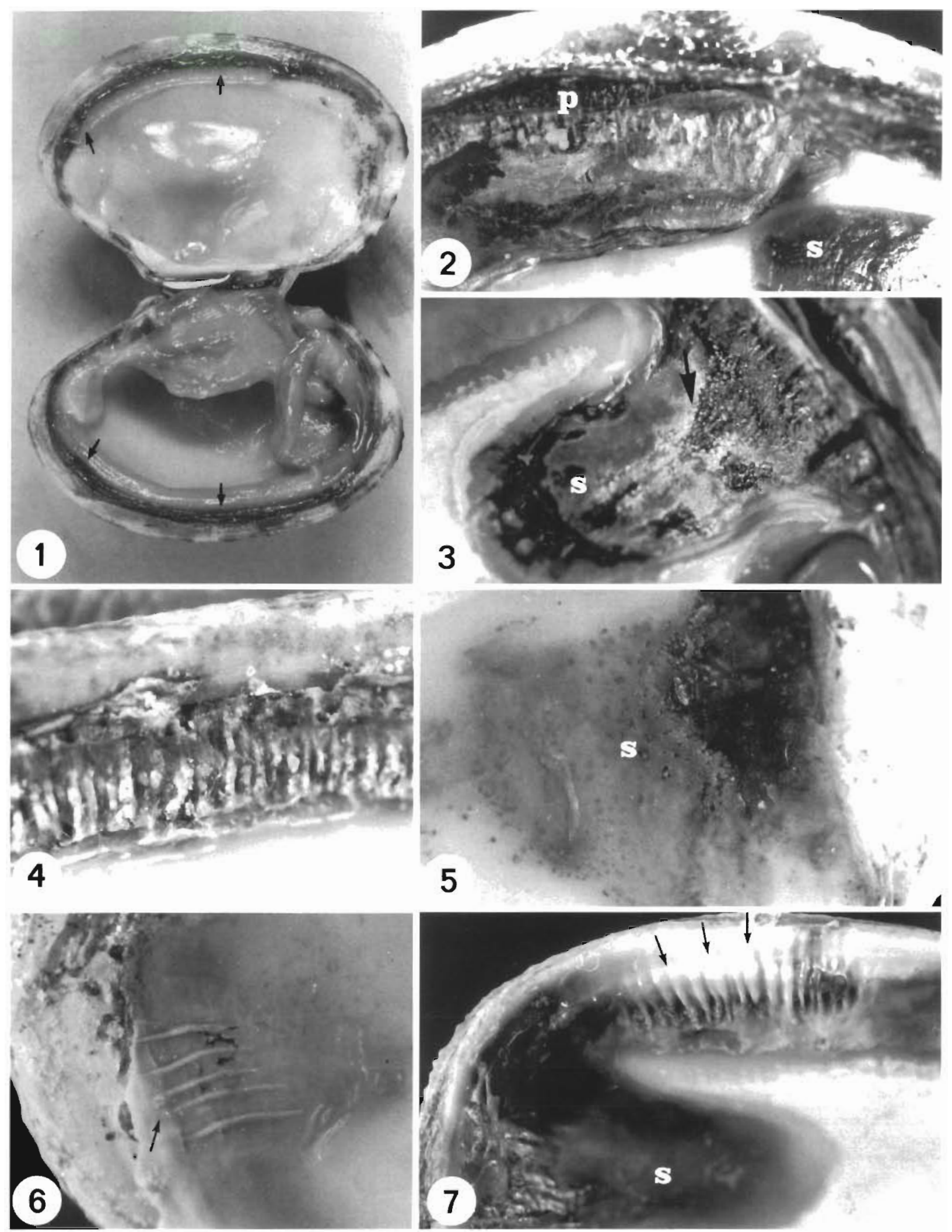

Figs. 1 to 7. Ruditapes philippinarum. Naturally diseased clams exhibiting the characteristic brown ring syndrome. s: sinusal compartment; p: peripheral compartment. Fig. 1. Brown organic material (arrows) adhering to the inner surface of the valves, between the pallial line and the edge of the shell. Fig. 2. Detail of the conchiolin deposit located in the peripheral and sinusal compartments. The deposit consists mainly of organic material; no shell repair process is observed. Clam collected in January 1988. Fig. 3. Conchiolin deposit in the sinusal compartment; some small calcified pearls (arrow) are joined side by side on the surface of the deposit. Clam collected in March 1988. Fig. 4. Deposit in the peripheral compartment; the crests of the deposit are covered by white calcified concretions which give it a flocculent appearance. Clam collected in March 1988. Fig. 5. Deposit partially covered by a wide transparent calcified plate in the sinusal compartment. Clam collected in April 1988. Fig. 6 . Newly formed calcified shell layer which completely covers the conchiolin deposit. Note the raised areas (arrow). Clam collected in June 1988. Fig. 7. Shell layers covering the deposit and showing several radially oriented raised areas (arrows). Clam collected in June 1988 


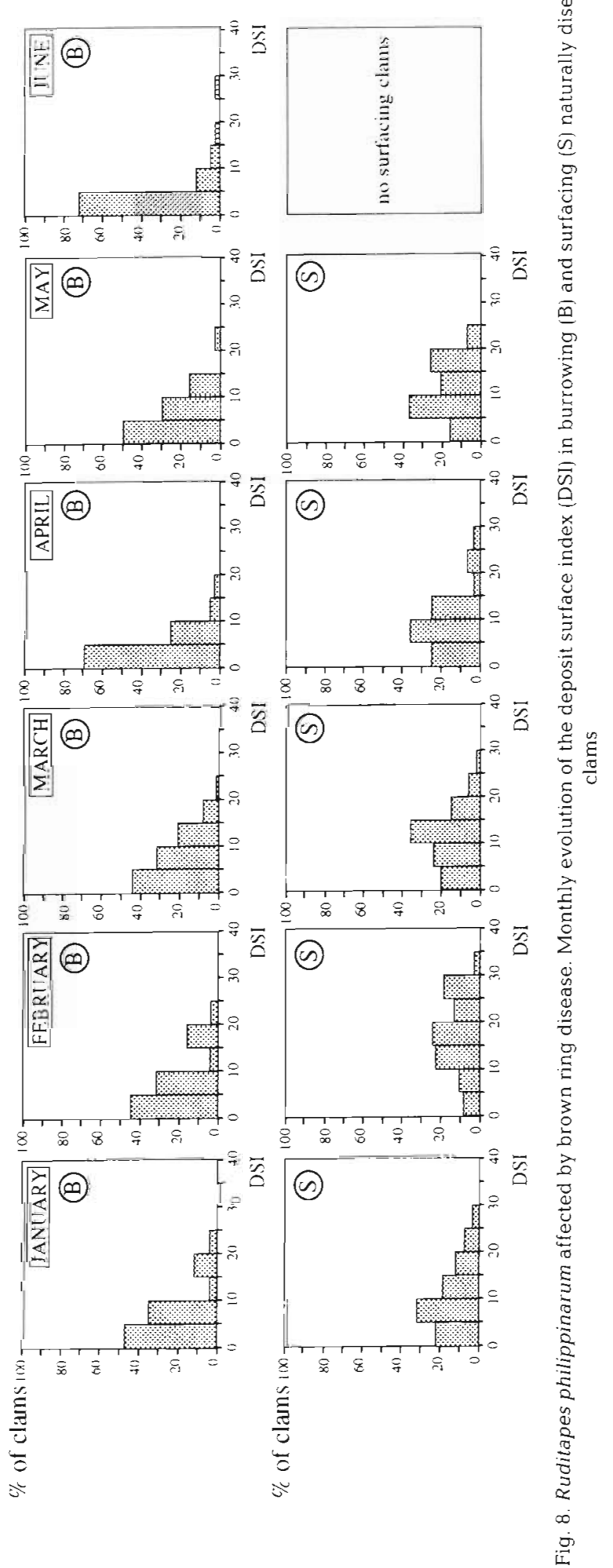

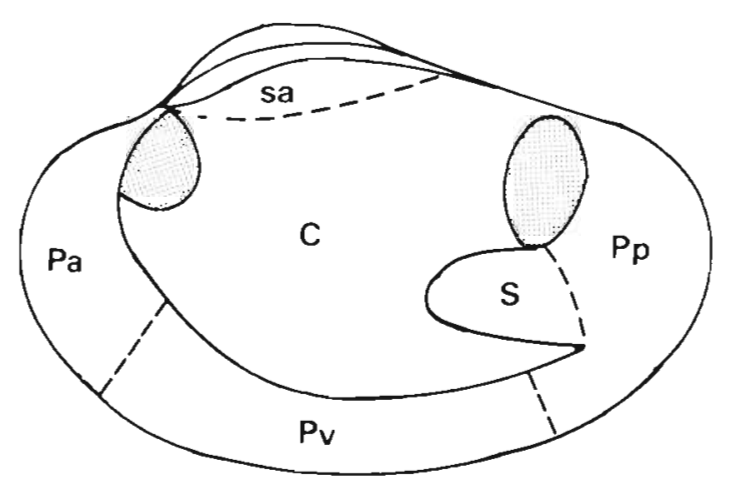

Fig. 9. Ruditapes philippinarum. Location of the different compartments and areas in the inner valve surface. C: central; $\mathrm{P}$ : peripheral [this compartment is subdivided into 3 areas, anterior $(\mathrm{Pa})$, ventral $(\mathrm{Pv})$ and posterior $(\mathrm{Pp})]_{\text {; }} \mathrm{S}$ : sinusal; sa: sub-articular

central and the sub-articular. The peripheral compartment can be further subdivided into 3 areas: ventral, posterior and anterior. Fig. 9 shows these divisions. Thus, the 2 valves comprise a total of 12 areas.

The same batch of 288 clams examined for DSI frequencies (see above) was used in this analysis. The distribution of the brown deposit by compartment was not significantly different between the right and left valves (Kolmogorov-Smirnov test of frequency comparison, $\mathrm{p}=0.01$ ). All the diseased valves possessed a brown deposit in at least the peripheral compartment. This compartment was also the only one affected in $79 \%$ of burrowing clams and in $64 \%$ of surfacing clams. The sinusal compartment was the second most frequently affected area, in 18\% and $34 \%$ of the valves of burrowing and surfacing clams respectively (Kolmogorov-Smirnov test of frequency comparison, $p=0.01$ ). The other compartments were rarely affected, representing from 0.3 to $1 \%$ of valves.

Because the peripheral compartment was so frequently affected, we were able to define 7 possible locations (i.e. combinations of areas affected) for the deposit: posterior ( $p)$, ventral (v), anterior (a), posteroventral ( $p v$ ), postero-anterior (pa), ventro-anterior (va) and the entire compartment (pva). Again, no significant difference was observed between left and right valves based on these 7 locations (KolmogorovSmirnov test of frequency comparison, $p=0.01$ ). The locations $\mathrm{p}, \mathrm{pv}$ and pva were the most frequently affected (10 to $62 \%$ of valves); the others were less frequently affected (1 to $5 \%$ ) (Table 1 ). The location $p$ was affected in more than $90 \%$ of valves in both types of clams. The frequencies of deposit distribution in these 3 locations, however, were significantly different 
Table 1 Ruditapes philippinarum. Frequency $(\%$ of values examined) with which various areas of the peripheral compartment were affected by the brown deposit, for burrowing and surfacing clams

\begin{tabular}{|lcc|}
\hline Location & Burrowing clams & Surfacing clams \\
\hline p & 34.5 & 10.5 \\
pv & 27.0 & 21.5 \\
pva & 24.0 & 62.0 \\
v & 3.5 & 1.0 \\
a & 4.5 & 1.0 \\
pa & 4.5 & 3.0 \\
va & 2.0 & 2.0 \\
\hline
\end{tabular}

between the 2 types of clams (Kolmogorov-Smirnov test of frequency comparison, $\mathrm{p}=0.01$ ).

The evolution of deposit distribution was followed monthly (Fig. 10). From February to May, the location pva was predominant in surfacing clams, occurring in 60 to $80 \%$ of specimens; it occurred in only $20 \%$ of burrowing clams. In June, no surfacing clams were found, and in burrowing clams, the frequency of pva fell to $8 \%$ whilst p was predominant at $53 \%$.

The predominance of certain areas of deposit in burrowing and surfacing clams suggests an evolution in the formation of the deposit, with a progression from 1 area in burrowing clams to 3 areas in surfacing clams. To investigate this hypothesis, the macroscopic progression of the deposit was followed after challenging healthy clams with VP1. One week after infection, a few brown spots appeared, generally on the inner surface of the shell edge. These spots were confined to a limited area $(p, v$ or $a)$ on the internal edge of the valve and were only visible with a binocular microscope (Fig. 11a, b). After $2 \mathrm{wk}$, the majority of the diseased clams exhibited numerous brown spots, distinctly visible to the naked eye but always localized (in site p, v or a) (Fig. 12). After $3 w \mathrm{k}$, the more developed disease was characterized by brown spots distributed fairly uniformly in 2 areas of the peripheral compartment ( $p v$, pa or va) (Fig. 13). One month after infection, from 10 to $60 \%$ of diseased clams exhibited brown spots which occupied the entire surface of the peripheral compartment (site pva), forming a complete brown ring (Fig. 14). The brown ring progressively thickened, became stratified and possibly invaded other compartments.

\section{Classification of the syndrome}

This macroscopic description of the syndrome permits us to establish a classification system. The syndrome is characterized by 2 reactions which may occur simultaneously in a given individual: formation of the conchiolin deposit, and shell repair. Two types of

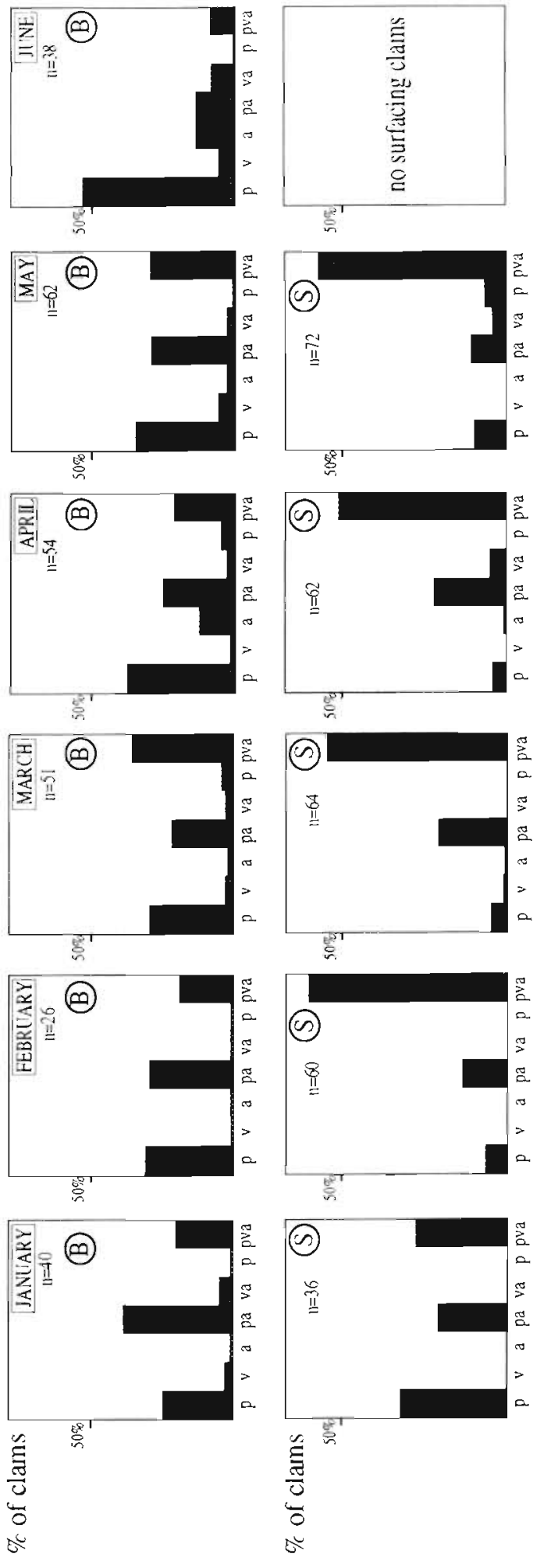


Figs, 11 to 14. Ruditapes philippinarum. Clams showing BRD syndrome produced by experimental infection with Vibrio P1. Fig. 11. (a) One week afler infection, the sign is not visible to the naked eve; it is located in a limited area of the peripheral compartment (inset). (b) Higher magnification of the inset showing an organic film and conchiolin spots which constitute the first signs of the disease. Fig. 12. Two weeks after infection, the conchiolin spots are still located in a limited area (arrows) but are visible to the naked eye. Fig. 13 Three weeks after infection, the conchiolin spots uniformly occupy half of the peripheral compartment. Fig. 1.4. One month after infection, the conchiolin spots occupy the entire surface of the peripheral compartment, forming the characteristic

brown ring, seen here on both valves
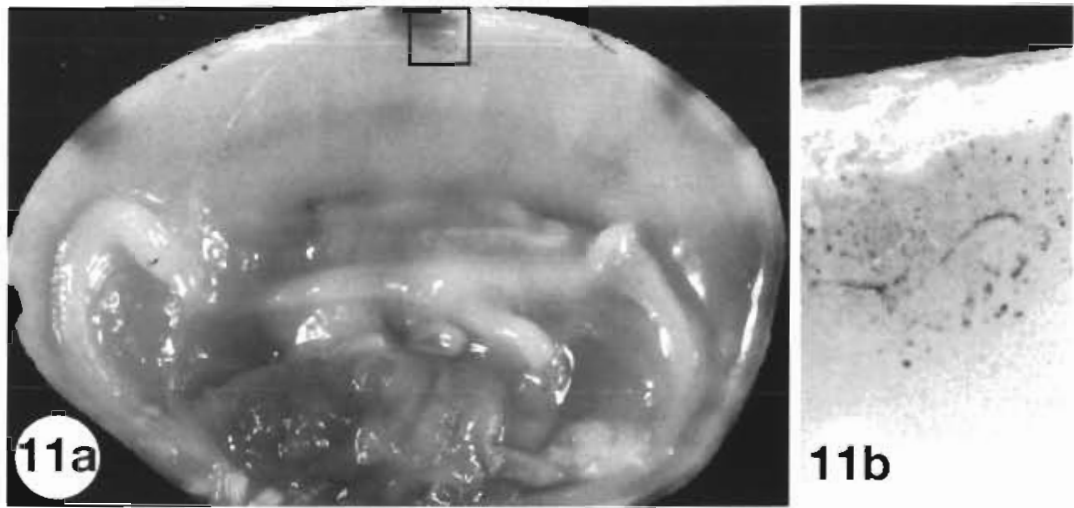

$11 b$

stages are therefore defined: conchiolin deposit stages (CDS) and shell repair stages (SRS).

\section{Conchiolin deposit stages}

The determination of CDS is based on the assessment of an index (TEI) which simultaneously takes into account the extent and the thickness of the deposit.

Initially, only the extent of the deposit is considered and an extent index (EI) is calculated, based on the number of areas affected by the brown deposit on the 2 valves:

\section{$E I=$ (no. of affected areas in peripheral compartment) + (no. of affected areas in other compartments) $\times 2$}

Therefore, the extent index can vary from 0 to 18. An area is counted even if it is only partially affected and even if binocular microscopy is necessary to identify the deposit. An EI value of 0 means that the clam appears to be healthy, i.e. there are no observable deposits at the binocular microscopic level; it could also mean that the clam was diseased but has completely recovered, i.e. the conchiolin deposit is completely covered by shell layers.

Subsequently, the EI is corrected in order to take deposit thickness into account. Four degrees of thickness were considered: (1) deposit not visible to the naked eye, but visible through a binocular microscope; (2) fine pale brown deposit or several small brown spots visible to the naked eye; (3) deposit with a thickness $<1 \mathrm{~mm}$; (4) thick deposit with
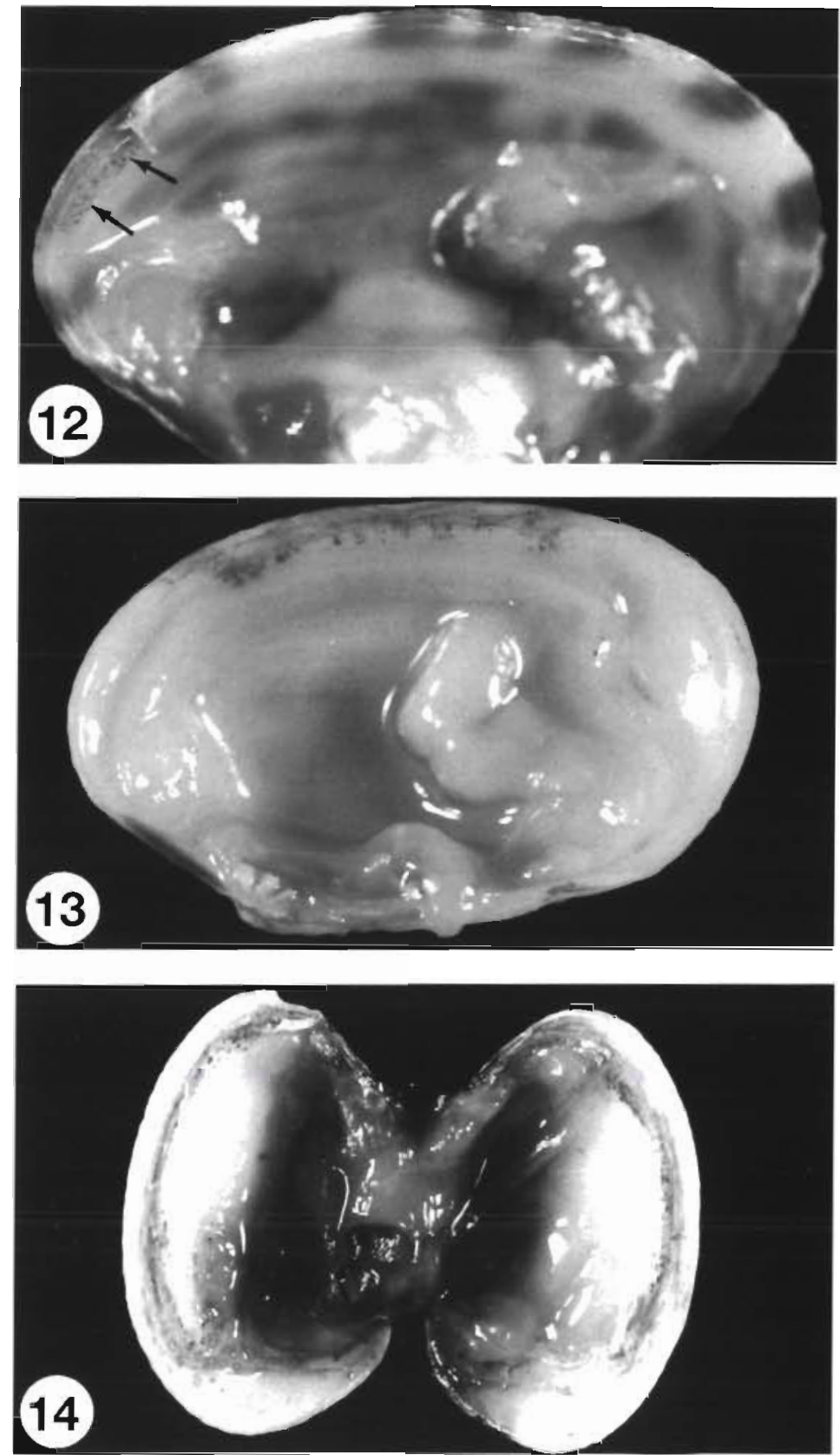
Table 2. Value of TEI, based on the degree of thickness (1 to 4) and the extent of the deposit
(1) $\mathrm{TEI}=-\mathrm{El}$
(2) TEI $=\mathrm{EI}-1$
(3) $\mathrm{TEI}=\mathrm{El}$
(4) $\mathrm{TEI}=\mathrm{EI}+1$

a thickness $\geq 1 \mathrm{~mm}$. The EI was corrected using these 4 degrees of thickness, yielding an index of thickness and extent (TEI) (Table 2). TEI can theoretically vary from -18 to 19. A healthy individual has no TEI.

The TEI values were grouped into 7 stages (CDS 1 to 7) which were related to the degree of disease development (Fig. 15). CDS 1 is not visible to the naked eye. CDS 2 corresponds to a limited extent of deposit (maximal TEI value: 2). From CDS 3 to 6 the TEI increases steadily, due to an increase in the extent of deposit. Several patterns of very extensive deposit (TEI 11 to 19) are grouped into CDS 7. which is considered the later stage of the disease. When the clams exhibit no deposit, the CDS is considered equal to zero.

\section{Shell repair stages}

Based on observations of naturally diseased clams, 3 stages of shell repair (SRS 1 to 3) are proposed. SRS 1 corresponds to the accretion of calcified material (Figs. 3 \& 4). The partial covering of the deposit by wide calcified plates corresponds to SRS 2 (Fig. 5). In SRS 3, the brown deposit is completely covered by shell layers (Figs. $6 \& 7$ )

Considering the processes of conchiolin deposit formation and shell repair together, 3 phases of the disease may be defined (Table 3). The first phase corresponds to the development of the disease and is characterized only by accumulation of a conchiolin deposit. The second phase is characterized by the simultaneous occurrence of both processes in a given individual. The third

Table 3. The 3 phases of BRD in Ruditapes philippinarum, based on both conchiolin deposit stages (CDS) and shell repair stages (SRS)

\begin{tabular}{|ccc|}
\hline Phase & CDS & SRS \\
\hline 1 & 1 to 7 & 0 \\
2 & 1 to 7 & 1 to 2 \\
3 & 0 & 3 \\
\hline
\end{tabular}

phase corresponds to the end of the recovery process, when the clams have totally covered the conchiolin deposit. Eventually, the situation may become chronic, and the formation of a new deposit on a previously recovered shell is observed; this could be considered the first phase of a second cycle of the disease.

\section{DISCUSSION}

Anomalies similar to the BRD syndrome have been reported by several authors. The presence of a conchiolin deposit has been associated with various etiological agents including chemical factors, environmental factors and parasites.

Pollutants have been shown to disturb the calcification process. Tributyltin may affect the shell chamber

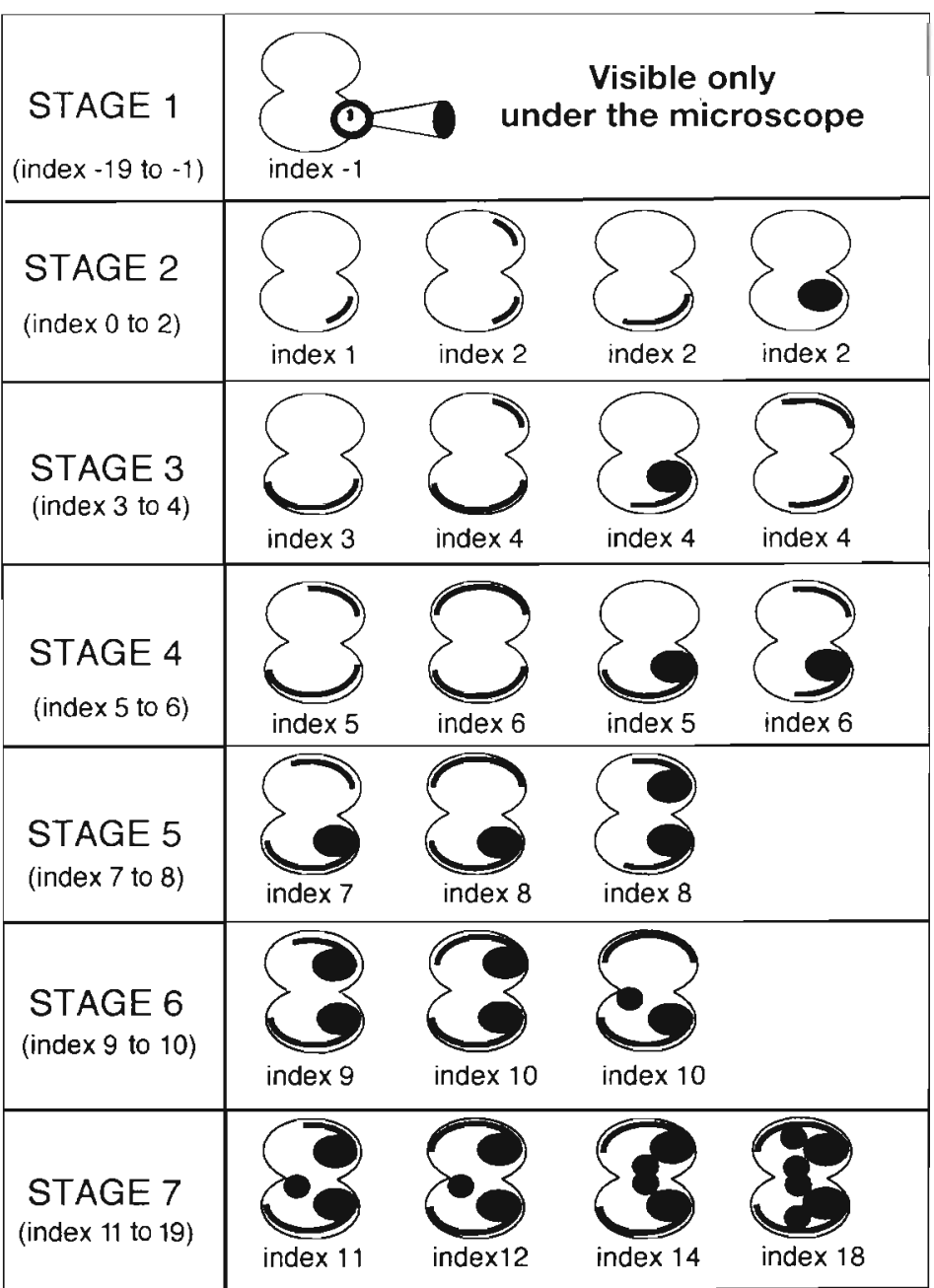

Fig. 15. Ruditapes philippinarum affected by brown ring disease. The 7 stages of conchiolin deposit as a function of the TEI. The most frequent areas of conchiolin deposit are illustrated for each stage 
of Crassostrea gigas (Alzieu et al. 1981). Diflubenzuron disturbs crystal arrangement and provokes an abnormal accumulation of organic material between the crystals on the inner surface of the valves of Anodonta cygnea (Machado et al. 1990). Gas-bubble disease, induced by oxygen oversaturation, is characterized by the presence of spots of conchiolin filled with gas bubbles on the inner surface of oyster and clam valves (Malouf et al. 1972). In the latter study the conchiolin deposit was later covered by shell layers.

Environmental factors responsible for metabolic deficiencies are also associated with conchiolin deposits. During spring and summer mortalities of Patinopecten yessoensis, moribund scallops were commonly characterized by shell deformities and the adhesion of a brown film-like substance on the inside of the shell margin (Mori 1975). Several factors were involved: cold temperatures during winter, nutritional deficiencies and high population densities. Mori (1975) was able to reproduce a similar syndrome in $P$. yessoensis under unfavorable culturing conditions. In the same species, Kawamata (1985) also associated conchiolin deposition with an abnormal development of the gonad during summer.

Parasites can also produce a similar syndrome. Trematodes are often associated with deposits of brown organic material on the inner surface of the valves in Donax vittatus (Dollfus 1912), Venerupis pullastra (Johannessen 1973) and Ruditapes aureus (Bartoli 1974). The deposits are often covered with calcified material which is filled with moribund metacercariae (Bartoli 1974). Conchiolinous pustules due to the protozoan Haplosporidium nelsoni were reported by Farley (1968) in MSX (multinucleate sphere unknown) diseased Crassostrea virginica. These pustules contain necrotic phagocytic cells and moribund parasites. A well-known shell disease which affects the oysters Ostrea edulis and Crassostrea angulata has been associated with a fungus (Alderman \& Jones 1971). The major syndrome is the development of white spots which become brown by deposition of conchiolin. In these spots, the fungus utilizes the organic matrix of the shell for its nutrition (Kohlmeyer 1969). Experimental challenge with pieces of diseased shells for 6 mo produced the shell disease syndrome in only $2 \%$ of the processed oysters (Alderman \& Jones 1971). However, $2 \mathrm{wk}$ after incubating healthy pieces of shell in seawater with a pure culture of Ostracoblabe implexa, this fungus was observed forming prochlamydospores, penetrating and growing over the entire shell (Raghukumar \& Lande 1988). Mortalities of Pinctada maxima (Pass et al. 1987) and Pinctada margaritifera (Marin \& Dauphin 1991) are also associated with brown-stained nacre between the mantle and the edge of the shell, but the etiology has yet to be clearly estab- lished. In Pecten maximus and Mercenaria mercenaria collected in Brittany, a brown-ring-like syndrome has been reported but VP1 was not found (Maes \& Paillard 1992). To date, in bivalves, bacteria have never been determined to be involved in a shell disease syndrome, and $B R D$ is probably the first bacterial shell disease described which affects bivalves at the adult stage

Another well-known reaction observed in bivalves is the process of shell repair after the organism has been subjected to various disturbances. After shell edge fracture, the pallial cells located underneath the fracture secrete 3 layers in succession: the periostracum, the prismatic layer and the inner layer (Watabe 1983, Pan \& Watabe 1989). During blister formation, bivalves may embed foreign bodies or parasites into shell layers in the same manner as the process of nacrezation described by Cheng (1967, 1981). This process occurs either when a foreign body is located between the mantle and the shell or when a bivalve closes galleries or holes caused by algae, fungi or worms (Jameson 1902). In BRD, a similar defense mechanism may be acting on the bacteria to embed them, at first through conchiolin deposition and then through accretion of shell layers, to limit their proliferation (Paillard 1992). All of these cases in which similar symptoms have different causes show that the BRD syndrome is not very specific and is a general reaction of bivalves to any aggression against the extra-pallial cavity.

In naturally occurring BRD syndrome in Ruditapes philippinarum, the deposit appears very heterogeneous in its location, its surface area and its structure. The differences in location and surface area of the deposit between the 2 categories of clams (burrowing and surfacing) may be considered partly responsible for the observed heterogeneity. Surfacing clams are more frequently and more extensively affected by the disease than burrowing clams. The experimentally produced syndrome was similar to the naturally occurring syndrome. The main difference was probably due to the fact that the natural deposits were often older than the 1 mo old artificially induced deposits; therefore the natural deposit was thicker, and several covering calcified layers were observed more often. The heterogeneous appearance of BRD syndrome in naturally diseased clams is due to the variability in deposit thickness and particularly to the occurrence of a partial shell repair process. The analysis of the precise sites of deposit suggests that it progresses from the area in contact with the siphons to the anterior area of the valves. Infestation of the clams by the pathogen could result from the retraction of the siphons between the 2 periostracal lamina. In the case of the fungal shell disease in Crassostrea angulata and Ostrea edulis, Alderman \& Jones (1971) showed that some areas of the shell were more frequently affected than others. This 
observation also seems to be directely related to the route by which the fungus infects the oyster shell.

The main contribution of the present paper is the elaboration of a classification system for BRD syndrome. This system is relatively complex because it takes into account the inherent complexity of the disease's symptoms. An important problem in classifying BRD syndrome results from the fact that the syndrome is characterized by the occurrence of 2 processes which can be simultaneous in any individual: conchiolin deposit formation and shell repair

Determination of the stage of conchiolin deposit formation is based on the calculation of the TEI, which considers principally the extent and, to a lesser degree, the location and thickness of the deposit. The extent alone satisfactorily describes the degree of disease development; infection experiments show that the deposit spreads progressively over time. The other characteristics (location and thickness) introduce minor corrections in the stage determination. Location was accounted for by weighting certain areas, i.e. introducing a multiplicative factor in scoring the areas principally affected in the more advanced stages of the disease. In addition, 4 degrees of thickness were considered. The first degree of thickness, corresponding to a deposit invisible to the naked eye, causes the TEI value to become negative; this is an arbitrary effect but it permits us to immediately distinguish CDS 1 from the other stages. The other 3 degrees of thickness correspond to deposits visible to the naked eye. A correction of -1 is applied for deposits composed of little spots, and +1 for deposits thicker than $1 \mathrm{~mm}$. This minor modification of the index value reflects the fact that an increase in thickness occurs after the process of deposit extension but is probably less important in terms of disease development.

In addition, the shell repair process is classified into 3 stages, which give an indication of the progress of recovery. The SRS is then associated with the CDS in order to define the 3 main phases of the disease: (1) accumulation and spreading of organic deposit, (2) stratification of organic and calcified layers, and (3) complete recovery. The establishment of these phases represents an attempt to define the different physiological states of diseased clams.

The classification developed in the present paper will be used in further epidemiological studies. It provides a way of measuring the effects of various environmental factors on the disease, and should allow a rapid comparison between different populations, localities and species.

Acknowledgements. This study was financed by the Commission of the European Communities within the framework of an F.A.R. program (contract no. AQ-3-763). It was also sup- ported by IFREMER and the Conseil Régional de Bretagne. The authors thank Alain Le Mercier for photographs and Alain Paimbeni and Cyrille for technical assistance. This is CNRS Publication No. 94011

\section{LITERATURE CITED}

Alderman, D. J., Jones, E. B. G. (1967). Shell disease of Ostrea equlis L. Nature 216: 797-798

Alderman, D. J., Jones, E. B. G. (1971). Shell disease of oysters. Fish. Invest. Ser. II 26(8): 1-19

Alzieu, C., Héral, M., Thibaud, Y., Dardignac, M. J., Feuillet, M. (1981). Influence des peintures antisalissures a base d'organostanniques sur la calcification de la coquille de l'huitre Crassostrea gigas. Revue Trav. Inst. Pêch. marit. 45(2): $101-116$

Bartoli, P. (1974). Recherches sur les Gymnophallidae F. N. Morozov, 1955 (Digenea), parasites d'oiseaux des côtes de Camargue: systématique, biologie et écologie. Thèse, Université Aix-Marseille

Cheng, T. C. (1967). Internal defense mechanisms. Adv. mar Biol. 5: 60-80

Cheng, T. C. (1981). Bivalves. In: Ratcliffe, N. A., Rowley, A. F (eds.) Invertebrate blood cells. Academic Press, London, p. $233-300$

Dollfus, R. P. (1912). Contribution à l'étude des trématodes marins des côtes du Boulonnais. Une méta-cercaire margaritigène parasite de Donax vittatus Da Costa. Mém. Soc. zool. Fr. 25: 85-144

Farley, C. A. (1968). Minchinia nelsoni (Haplosporidia) Disease Syndrome in the American oyster Crassostrea virginica. J. Protozool. 15: 585-599

Jameson, H. L. (1902). On the origin of pearls. Proc. zool. Soc. Lond. 1. 140-166

Johannessen, O. H. (1973). Deformations of the inner shell surface of Venerupis pullastra (Montagu) (Lamellibranchia) as a result of infection by a trematode metacercaria with a note of parasitism leading to parasitic castration. Sarsia 52: 117-122

Kawamata, K. (1985). Gonadal development of cultured scallops, Patinopecten yessoensis (Jay), of Rumoi (Hokkaido). Scient. Rep. Hokkaido Fish. expl. Stn 31 9-13

Kohlmeyer, J. (1969). The role of marine fungi in the penetration of calcareous substances. Am. Zool. 9: 741-746

Machado, J., Coimbra, J., Castilho, F., Sa, C. (1990). Effect of Diflubenzuron on shell formation of the freshwater clam, Anadonta cygnea. Archs environ. Contam. Toxicol. 19: $35-39$

Maes, P. (1992), Pathologie bactérienne chez deux invertébrés marins. La maladie des lésions vertes des échinides réguliers et la maladie de l'anneau brun de la palourde Ruditapes philippinarum. Thèse de doctorat. Université de Bretagne Occidentale, Brest

Maes, P., Paillard, C. (1992). Effet de Vibrio P1, pathogène de Ruditapes philippinarum sur d'autres espèces de bivalves. Haliotis 22: $141-148$

Malouf, R., Keck, R., Maurer, D., Epifanio, C. (1972). Occurrence of gas-bubble disease in three species of bivalve molluscs. J. Fish. Res. Bd Can. 29: 588-589

Marin, F., Dauphin, Y. (1991). Diversité des altérations dans la composition en acides aminés de la phase organique de la nacre des huitres perlières de Polynésie française (Pinctada margaritifera) atteintes par l'épizootie. C. r. Acad. Sci., Paris 312(3): 483-488

Mori, K. (1975). Seasonal variation in physiological activity of 
scallops under culture in the coastal waters of Sanriku district, Japan, and a physiological approach of a possible cause of their mass mortality. Bull. mar. Biol. Stn Asamushi Tohoku Univ. 15(2): 59-79

Paillard, C. (1992). Etiologie et caractérisation de la maladie de l'anneau brun chez la palourde d'élevage Ruditapes philippinarum. Thèse de doctorat, Université de Bretagne Occidentale, Brest

Paillard, C., Maes, P. (1990). Etiologie de la maladie de l'anneau brun chez Tapes philippinarum: pathogénicité d'un Vibrio sp. C. r. Acad. Sci., Paris 310(3): 15-20

Paillard, C., Percelay, L., Le Pennec, M., Le Picard, D. (1989). Origine pathogène de l'anneau brun chez Tapes philippinarum (Mollusque, Bivalve). C. r. Acad. Sci., Paris 309(3): 235-241

Responsible Subject Editor: A. K. Sparks, Seattle, Washington, USA
Pan, C. M., Watabe, N. (1989). Periostracum formation and shell regeneration in the lingulid Glottidia pyramidata (Brachiopoda: inarticulata). Trans. Am. Microsc. Soc. 108(3): 283-298

Pass, D. A., Dybdahl, R., Mannion, M. M. (1987). Investigations into the causes of mortality of the pearl oyster, Pinctada maxima (Jamson), in Western Australia. Aquaculture 65: 149-169

Quayle, D. B. (1969). Pacific oyster culture in British Columbia. Bull. Fish. Res. Bd Can. 169: 1-192

Raghukumar, C., Lande, V. (1988). Shell disease of rock oyster Crassostrea cucullata. Dis. aquat. Org. 4: 77-81

Watabe, N. (1983). Shell repair. In: Saleuddin, A. S. M., Wilbur, K. M. (eds.) The Mollusca, Vol. 4. Academic Press, London, p. 289-316

Manuscript first received: January 28, 1993

Revised version accepted: February 16, 1994 